\title{
Long-term responses of zooplankton to invasion by a planktivorous fish in a subarctic watercourse
}

Per-Arne Amundsen*, Anna Siwertsson*, Raul Primicerio* \& Thomas Bøhn*§

* Department of Aquatic Biosciences, Norwegian College of Fishery Science, University of Tromsø, Tromsø, Norway

§ Norwegian Institute of Gene Ecology, Breivika, Tromsø, Norway

Correspondence: Per-Arne Amundsen, Norwegian College of Fishery Science, University of Tromsø, N-9037 Tromsø, Norway.

E-mail: Per-Arne.Amundsen@nfh.uit.no

Keywords: invasion, zooplankton, planktivory, Daphnia, Bosmina, predation

Published in Freshwater Biology (2009) 54, 24-34. doi: 10.1111/j.1365-

2427.2008.02088.x 
Summary

1. Introduced or invading predators may have strong impacts on prey populations of the recipient community mediated by direct and indirect interactions. The long-term progression of predation effects, covering the invasion and establishment phase of alien predators, however, has rarely been documented.

2. This paper documents the impact of an invasive, specialised planktivorous fish on its prey in a subarctic watercourse. Potential predation effects on the crustacean plankton, at the community, population and individual levels, were explored in a long-term study following the invasion by vendace (Coregonus albula).

3. Over the 12-yr period, the density and species richness of zooplankton decreased, smaller species became more abundant, and Daphnia longispina, one of the largest cladocerans, was eliminated from the zooplankton community.

4. Within the dominant cladocerans, including Daphnia spp., Bosmina longispina and Bosmina longirostris, the body size of ovigerous females and the size at first reproduction decreased after the arrival of the new predator. The clutch sizes of Daphnia spp. and $B$. longirostris also increased.

5. Increased predation pressure following the vendace invasion induced many effects on the crustacean zooplankton, and we document comprehensive and strong direct and indirect longterm impacts of an introduced non-native predator on the native prey community. 


\section{INTRODUCTION}

The introduction of alien species represents one of the greatest threats to global biodiversity (Gido \& Brown, 1999; Davis, 2003). Introduced predators may have a particularly strong impact on recipient communities due to a high vulnerability of naïve prey to new predators (Park, 2004). Prey naiveté is most common in freshwater ecosystems (Cox \& Lima, 2006), and isolated environments like lakes and islands are particularly sensitive to predator introductions (Kaufman, 1992; Courchamp et al., 2003). In lakes, invasive predators may even be able to drive native species to extinction (Zaret \& Paine, 1973; Witte et al., 1992). Classic examples of strong predatory impacts include lacustrine introductions of planktivorous fish that have caused extinction of large-sized zooplankton species (Hrbáček et al., 1961; Brooks \& Dodson, 1965).

Most studies of predation effects on zooplankton are short-term comparisons of the prey communities before and after predator introductions, or comparisons of similar systems with and without the predator (Hrbáček et al., 1961; Brooks \& Dodson, 1965; Hall et al., 1976; DeMelo, France \& McQueen, 1992). Such short-term surveys may lack the power to separate weak trends from natural variations (Elliott, 1994). Furthermore, such snapshot studies can not distinguish between direct and indirect effects of predator introductions, and do not provide any information on the transitory dynamics between different prey community states. Thus, based on short-term studies, it is not possible to conclude which mechanisms drive the changes in the prey community or to quantify the rates of change, precluding in-depth understanding and predictions. Long-term studies of predator impact on prey are necessary to obtain information on relevant mechanisms and transient dynamics, but have rarely been performed (Strayer et al., 2006). The present contribution relates to the introduction and 
invasion of an alien fish species, the vendace Coregonus albula (Linnaeus, 1758), in a subarctic watercourse, examining the long-term effects on the planktonic prey community over a 12-yr period during the establishment of this specialised zooplanktivore.

Predation by planktivorous fish has large impacts on the dynamics and structure of zooplankton communities (Zaret, 1980; Lazzaro, 1987; Gliwicz \& Pijanowska, 1989). The primary, direct effect is an increased mortality rate of the prey. However, predation is often highly selective and most planktivorous fish are visual predators that select the largest visible prey (O'Brien, 1987; Gliwicz \& Pijanowska, 1989; Lampert \& Sommer, 1997). Cladocerans are often preferred prey since they have a conspicuous pattern of motion (Zaret, 1980) and are easy to capture compared to copepods which have a more effective escape response (O'Brien, 1987; Lampert \& Sommer, 1997). The egg clutches carried by gravid cladocerans may further increase their vulnerability, and selection of ovigerous females and females carrying a large number of eggs may strengthen the predation effects on prey density, composition and demography (Gliwicz, 1981; Dawidowicz \& Gliwicz, 1983).

In addition to the numerical, direct effects of predation, prey populations may be affected by invasive predators via trait-mediated interactions (Bolker et al., 2003). Several cladoceran species are able to adjust their life-history in response to increased predation risk detected via chemical cues associated with digested prey (Stabell, Ogbebo \& Primicerio, 2003; Pohnert, Steinke \& Tollrian, 2007). Cues associated with predation risk from fish are known to anticipate the onset of reproduction in order to increase the chance of reproducing successfully before being eaten (Taylor \& Gabriel, 1992; Larsson \& Dodson, 1993; Lass \& Spaak, 2003). Accordingly, in several cladoceran species a smaller size at first reproduction has been demonstrated to occur with increasing predation pressure from fish (Stibor, 1992; 
Vonder Brink \& Vanni, 1993; Weber \& Declerck, 1997). Clutch size has also been found to increase when predation from fish intensifies (Dodson, 1989; Stibor, 1992; Vonder Brink \& Vanni, 1993). Hence, increased predation from planktivorous fish may result in a multitude of effects, mediated by direct and indirect interactions, including a decrease in zooplankton abundance (Gliwicz, 1981; Hamrin \& Persson, 1986; Persson et al., 2004), changes in community and population structure towards smaller species and smaller individuals within the species (Brooks \& Dodson, 1965; Hall, Cooper \& Werner, 1970), life-history modifications (Stibor, 1992; Weider \& Pijanowska, 1993) and morphological adaptations (Dodson, 1988, 1989; Kolar \& Wahl, 1998).

Few studies have addressed the impacts of zooplanktivore fish in subarctic and arctic systems and, to our knowledge, long-term studies of the impact of invasions in the subarctic are absent. These systems are presently undergoing changes associated with climate warming that are expected to favour the successful invasion of specialist planktivores (Primicerio et al., 2007). It is therefore important to document and understand the long-term implications of such invasions. In the subarctic Pasvik water system, northern Norway, the opportunity to study long-term ecological responses during the establishment of an alien predator arose when vendace invaded the watercourse in the late 1980's (Amundsen et al., 1999). The vendace is a highly specialised zooplanktivore (e.g., Svärdson, 1976; Hamrin, 1983; Bøhn \& Amundsen, 1998) and established successfully as the dominant pelagic fish species during the 1990’s (Amundsen et al., 1999; Bøhn et al., 2004). Whitefish (Coregonus lavaretus (Linnaeus, 1758)) dominated the native limnetic fish community, but has been displaced from the pelagic habitat due to competitive interactions with vendace (Amundsen et al., 1999; Bøhn \& Amundsen, 2001, Bøhn et al., 2008). The vendace thus represents a new and highly efficient predator of the native crustacean plankton. The trends in the zooplankton community following the 
invasion were studied from 1991 to 2002, with particular emphasis on the dominant cladoceran genera; Bosmina and Daphnia. The following changes were expected as a response to increased predation pressure: (i) decreased total density of crustacean zooplankton and reduced relative abundance of larger species; (ii) reduced diversity in the prey community; (iii) reduced body size of ovigerous female cladocerans; and (iv) decreased body size at first reproduction and increased clutch size at a given body size in cladocerans.

\section{METHODS}

\section{Study area}

The Pasvik water system $\left(69^{\circ} \mathrm{N}, 2^{\circ} \mathrm{E}\right)$ originates from Lake Inari $\left(1102 \mathrm{~km}^{2}\right)$ in Finland, runs into Russia and then defines the border between Norway and Russia for a length of about 120 $\mathrm{km}$. The Norwegian-Russian part of the system has a total area of $142 \mathrm{~km}^{2}$, a catchment area of $18404 \mathrm{~km}^{2}$ and a mean annual flow of about $175 \mathrm{~m}^{3} \mathrm{~s}^{-1}$. There are presently seven impoundments. Most rapids and waterfalls have disappeared, and today lakes and reservoirs dominate the system. Water level fluctuations are small, usually less than $0.8 \mathrm{~m}$. The geology in the region is dominated by gneiss bedrock. The landscape is covered by birch- and pinewoods interspersed with wetlands and bogs. Mean annual air temperature is low $\left(-0.3^{\circ} \mathrm{C}\right)$ and minimum and maximum monthly mean temperatures are $-13.5^{\circ} \mathrm{C}$ and $+14.0^{\circ} \mathrm{C}$, respectively. Precipitation in the area is low, with an annual mean of $358 \mathrm{~mm}$.

The study was carried out in Lake Ruskebukta in the upper part of the catchment. Lake Ruskebukta (69 $13^{\prime} \mathrm{N}, 2^{\circ} 14^{\prime} \mathrm{E}$; $52 \mathrm{~m}$ a.s.l.) has an area of $5.3 \mathrm{~km}^{2}$, and a maximum depth of $15 \mathrm{~m}$. The lake is dimictic, oligotrophic and humic with a Secchi-depth from 2-4 m. The total 
phosphorus and nitrogen concentrations usually range between 10-20 and 300-400 $\mu \mathrm{g} \mathrm{L}^{-1}$, respectively. The ice-free season lasts from late May or early June, to the end of October or early November.

Altogether 15 fish species have been recorded in the Pasvik water system. The most common species in the lakes are whitefish (Coregonus lavaretus), perch (Perca fluviatilis Linnaeus, 1758), pike (Esox lucius Linnaeus, 1758), burbot (Lota lota (Linnaeus, 1758)), nine-spined sticklebacks (Pungitius pungitius (Linnaeus, 1758)) and brown trout (Salmo trutta Linnaeus, 1758). The whitefish consists of two different morphs, differentiated by the morphology and number of gill rakers and referred to as sparsely and densely rakered whitefish (Amundsen, Bøhn \& Våga, 2004a).

The vendace invasion

Vendace (Coregonus albula) invaded the watercourse in the late 1980’s after being introduced to Lake Inari in the 1960’s (Amundsen et al., 1999; Bøhn \& Amundsen, 2001). By 1995, vendace had established populations along the whole Pasvik system (Amundsen et al., 1999). Prior to the invasion of vendace, whitefish was the dominant fish species both in the pelagic, profundal and littoral habitats of the lakes and reservoirs in the catchment (Amundsen et al., 1999). After the invasion of vendace, the whitefish has been displaced from the pelagic zone and vendace has become the dominant pelagic species (Bøhn \& Amundsen, 1998, 2001; Amundsen et al., 1999; Bøhn et al., 2004, 2008). In Ruskebukta, vendace was observed for the first time in 1991. The abundance of vendace increased rapidly and it has, since 1992, been the dominant species in gillnet catches from the pelagic zone of the lake (Fig. 1; see also Amundsen et al., 1999; Bøhn et al., 2004, 2008). Vendace and whitefish are the only fish species in the lake that feed extensively on zooplankton. Juvenile perch also take zooplankton, 
but perch are rarely caught in the pelagic zone and their ontogenetic shift to zoobenthos occurs at an early stage (Amundsen et al., 2003).

Field sampling and laboratory analyses

Zooplankton was sampled annually in the middle of September in the 12-yr period from 1991-2002, except for 1994, 1996 and 2001. In late summer differences between years are usually least pronounced (Sarvala et al., 1998), while there is still a strong impact of predation. Integrated zooplankton samples were collected using a plankton net with $90 \mu \mathrm{m}$ mesh size hauled vertically from the deepest part of the sampling site $(15 \mathrm{~m})$ to the surface. Sampling was performed at noon and three replicate hauls were usually taken. The zooplankton samples were preserved in a $4 \%$ formaldehyde solution.

Individuals of the different species of crustacean plankton were identified and counted using a binocular microscope with 40X magnification. A sub-sample was taken from each vertical haul, and a minimum of 150 (mean 400) individuals was counted. When possible, two or more vertical hauls were analysed from each year, and the mean values were used in the further calculations. Zooplankton density was standardized to the number of individuals per vertical haul. All cladocerans and adult copepods were identified to species, whereas early copepodite stages were only classified as cyclopoids or calanoids.

Two of the Daphnia species present in the Pasvik water system, Daphnia cristata Sars and Daphnia longiremis Sars, are not easily separated. They were therefore counted together and are referred to as Daphnia spp. Of the two species, D. cristata was always the most common. The two Bosmina species present, Bosmina longispina (O.F.M) and Bosmina longirostris Leydig, were identified to species based on morphological characteristics, and this method 
was validated by identifications based on the position of the head pores (see Goulden \& Frey, 1963). To locate the pores, the animals were bleached with chlorine. The relative abundance of the two Bosmina species was calculated from sub-samples ( $\mathrm{n}>100)$.

From each sampling occasion, the body size of Daphnia spp. was measured under a binocular microscope with $40 \mathrm{X}$ magnification on 50 females and, when possible, on up to 40 females with subitaneous eggs. Two size measurements were used: body length was measured from the base of the tail spine to the top of the head, and carapace length as the body length without the head. The number of subitaneous eggs or ephippia was counted where present. Body length of the two Bosmina species was also measured under a microscope (100 X). Measurements were continued until 50 individuals of each species, and in addition 50 females with eggs, had been measured. In a few samples there were not enough females with eggs to satisfy this criterion. For all individuals measured the number of eggs or ephippia was counted.

\section{Statistical analyses}

Linear and logistic regression models were used to test hypotheses. All data were inspected for normality of distribution and variance homogeneity. Statistical analyses were carried out using SYSTAT software (Systat Software Inc., San Jose, California, USA).

The body size distributions of Daphnia spp., B. longispina and B. longirostris were analysed with special emphasis on females with eggs, as they are expected to be most affected by fish predation. A linear regression relating body length to sampling year was conducted for each species to look for trends over the whole study period. The size at first reproduction was further estimated for these three taxa by logistic regression analyses in terms of the median effective level (EL50, see Agresti, 2002), which defines the smallest body size at which 50\% 
of the individuals are egg-bearing. Further, logistic regression models were used to examine trends in size at first reproduction during the study period, relating the probability of having eggs to body size and year.

Clutch size of females carrying subitaneous eggs was examined in Daphnia spp. and B. longirostris. Binary logistic regressions were performed with the number of eggs (one or two) as the dependent variable, and body length and year as independent variables. Larger clutch sizes (three-four eggs) were not included since they were rare. Bosmina longispina was not included in this analysis due to the presence of few females with eggs.

\section{RESULTS}

\section{Density and community structure}

The total density of crustacean zooplankton showed a strong negative trend during the study period, including a sharp decrease from 1991 to 1993, followed by a recovery in abundance in 1995, and thereafter a steep decline towards 2002 (Fig. 2a). From 1991 to 2002 the density was reduced by approximately $85 \%$, a tendency followed by all the analysed zooplankton species except Bosmina longirostris. The declining trend was not statistically significant over the total sampling period, however, due to extreme values of zooplankton density recorded in 1993 and 1995 (Linear regression; $\mathrm{P}=0.124$ ). The peak in 1995 was related in particular to a high density of $B$. longirostris. Excluding this species from the analyses gave a significant overall decline in the total density of other zooplankton species over the time period from 1991 to 2002 (Linear regression; $\mathrm{P}<0.05, \mathrm{R}^{2}=0.44$ ). 
Eleven crustacean plankton species were observed during the study, including eight cladocerans and three copepods. The most abundant cladocerans were Bosmina longirostris, Bosmina longispina and Daphnia cristata, whereas Daphnia longiremis, Daphnia longispina (O.F.M), Ceriodaphnia quadrangula (O.F.M), Holopedium gibberum Zaddach and Leptodora kindtii (Focke) occurred more occasionally. The three copepods were Cyclops scutifer Sars, Eudiaptomus graciloides Liljeborg and Eudiaptomus gracilis Sars. The largest Daphnia species, D. longispina, was recorded only in the first year of study (i.e. 1991), when the highest species diversity was also observed (Fig. 2b). The species diversity decreased throughout most of the study period, but recovered again in 2002.

Cladocerans dominated the zooplankton community throughout the study (Fig. 2c). Daphnia spp. was most abundant among the cladocerans in the early years, whereas Bosmina spp. became more important later in the study. Within the genus Bosmina there was a large change in species composition. Bosmina longispina dominated in 1991, whereas the smaller $B$. longirostris was dominant in all the subsequent years except 1998. Hence, the proportion of $B$. longispina declined strongly during the study period (Fig. 3).

\section{Body size distribution}

The body length of females with eggs decreased significantly during the study period in the cladoceran species analysed (Fig. 4; Table 1 ; linear regression: $\mathrm{P}<0.001$ for all species). The largest relative decline in body size was seen in B. longispina followed by Daphina spp, whereas the least decline was observed in the smallest cladoceran B. longirostris.

\section{Reproduction}


The size at first reproduction decreased significantly over the study period for the two Bosmina species (Fig. 5; Table 2; logistic regression: $\mathrm{P}<0.001$ for both species), with the largest decrease being observed in B. longispina. The size at first reproduction also decreased significantly in Daphnia spp. during the study, but with a less clear-cut trend than for the Bosmina species (Table 2; logistic regression: $\mathrm{P}<0.05$ ).

The clutch sizes of Daphnia spp. and B. longirostris increased significantly during the study (Table 3; logistic regression: $\mathrm{P}<0.01$ ). In both species, most gravid females had one or two eggs. In the total material of 370 Daphnia spp. with eggs, only five individuals were found with three eggs and two with four eggs, and most of these were found in the year 2000. Similarly, B. longirostris with more than two eggs were rare in the samples. Out of a total of 448 females with eggs, only 13 and five individuals with three and four eggs, respectively, were found.

\section{DISCUSSION}

Throughout the whole study, the zooplankton community in Ruskebukta was dominated by small cladocerans, in particular D. cristata, B. longispina and B. longirostris. Together with small cyclopoid copepods and rotifers, these species are usually the most common zooplankton in lakes dominated by vendace (Hamrin, 1983; Viljanen, 1983; Kankaala et al., 1990; Løvik \& Kjellberg, 2003). High predation pressure from fish generally results in a zooplankton community consisting of small species, whereas more competitive larger species tend to dominate in the absence of planktivorous fish (Brooks \& Dodson, 1965; Hall et al., 1976; Gliwicz, 1990). Prior to the invasion by vendace of the Pasvik system, densely rakered 
whitefish were abundant, dominating the planktivorous assemblage in the pelagic zone. This whitefish morph is a specialised zooplanktivore (Svärdson, 1976; Bøhn \& Amundsen, 2001; Amundsen et al., 2004a, b) that may impose a strong predation pressure on its prey, as reflected by the dominance of small-sized cladocerans even at the onset of vendace invasion . But vendace were still able to induce a marked change in the community composition towards a predominance of even smaller zooplankters, demonstrating its highly specialised abilities as a zooplanktivore.

The diversity of zooplankton declined after the vendace invasion, mainly due to a reduced contribution, and even disappearance, of the largest-sized cladoceran species. The largest Daphnia species observed in the present study, D. longispina, was recorded in 1991, but was thereafter not represented in the zooplankton samples. Species in the D. longispina group are usually highly selected by planktivorous fish (Hamrin, 1983; Sandlund, Næsje \& Kjellberg, 1987; Karjalainen \& Viljanen, 1993), and extinction of large cladocerans after invasions of planktivorous fish has also been documented in earlier studies (Hrbáček et al., 1961; Brooks \& Dodson, 1965). Another distinct change in the zooplankton species composition was observed within Bosmina with a shift from a predominance of B. longispina in 1991 to a subsequent dominance by B. longirostris. Bosmina longirostris was the smallest cladoceran present in the zooplankton community in Ruskebukta, and was thus assumed to be least affected by fish predation. Vendace were also found to exhibit a negative selectivity for $B$. longirostris in an earlier study in the system (Bøhn \& Amundsen, 1998).

The total zooplankton density in Ruskebukta decreased over the study period, and Daphnia spp. and B. longispina, the two largest of cladocerans that were common, displayed the sharpest declines. Both $B$. longispina and $D$. cristata are known to be able to coexist with 
planktivorous fish (Hamrin, 1983; Kankaala et al., 1990), B. longispina due to its high reproductive rates (O'Brien, 1979), and D. cristata due to its transparent body and effective defence strategies, including diel vertical migration and life-history changes (Pijanowska, 1992). In spite of these characteristics, the relative abundance of both species decreased after the vendace invasion. High densities of vendace have been shown to decrease the total abundance and biomass of pelagic crustaceans (Hamrin, 1983; Karjalainen et al., 1997; Sarvala et al., 1998; Bøhn \& Amundsen, 1998). Furthermore, in several studies addressing the food preference of vendace, $B$. longispina and/or $B$. coregoni were the preferred prey, and $D$. cristata was also important prey (Hamrin, 1983; Viljanen, 1983; Kankaala et al., 1990; Karjalainen \& Viljanen, 1993; Bøhn \& Amundsen, 1998). The present findings confirm that efficient and selective predation by vendace may have very strong effects on the density and composition of the zooplankton community, and also demonstrate the impact of an invading predator on its prey community.

The introduction of vendace to Lake Inari and the Pasvik water system has transferred the species outside its native range (Amundsen et al., 1999), but the general distributions of this new predator and the array of zooplankton species living in the study lake overlap widely, suggesting that these species may have co-evolved as predator and prey. Even though the most serious consequences of alien species are expected when prey species have had no common evolutionary history with the introduced predator, we show that more or less all of the hypothesised effects have occurred. One factor that may have aggravated the predation effects in this specific case is the low productivity of the system. Theoretical models and experiments have in this respect demonstrated that high predation pressure decreases diversity at low productivity, although the diversity may increase when productivity is high (Worm et al., 2002). 
Within the dominant cladoceran species there was a gradual decrease in body size over the study period. As expected, the greatest size reductions were found among the two largest species (Daphnia spp. and B. longispina). Increased predation pressure from fish generally causes reduced body size in cladocerans due to a selection of the largest prey present (Zaret, 1980; O'Brien, 1987; Lampert \& Sommer, 1997). In addition, predation pressure tends to be even stronger on females with eggs, due to their increased visibility (Mellors, 1975). Even the smallest cladoceran B. longirostris significantly decreased in size during the study, although the absolute change over time was relatively small. Bosmina longirostris has also been found in other studies to decrease in size in the presence of planktivorous fish (Salo et al., 1989; Vonder Brink \& Vanni, 1993; Ślusarczyk, 1997; Bøhn \& Amundsen, 1998), supporting the conclusion that the observed trends are related to increased predation pressure from the invader. The decrease in size of $B$. longirostris also reflects the ability of vendace to exploit very small prey items, confirming its high efficiency as a planktivore.

The size at first reproduction also decreased during the study period in all the examined cladoceran species, and B. longispina seemed to be the most affected. Reduced size at maturity is an effective way to cope with increased predation pressure from planktivorous fish, allowing individuals to start reproducing before they are exposed to strong size-selective predation (Taylor \& Gabriel, 1992; Larsson \& Dodson, 1993; Lass \& Spaak, 2003). Size at first reproduction is known to be an inducible life-history trait in cladocerans (Stibor, 1992; Weider \& Pijanowska, 1993), but reduced size at reproduction may also be an indirect consequence of size-selective predation from fish due to maternal size effects (Lampert, 1993; Stibor \& Lampert, 2000). In Daphnia, maternal size strongly influences size at first reproduction: small-sized females produce small eggs hatching into small neonates, which 
again are small when they reproduce for the first time (Ebert, 1993; Lampert, 1993; Tollrian, 1995). Size at first reproduction estimated in field populations may furthermore depend on the proportion of females carrying their first brood, since eggs in the first clutch are smaller than in later clutches (Lampert, 1993). Size-selective predation from fish increases the proportion of females carrying their first brood, which results in a decreased size at first reproduction. Whatever the actual mechanisms are in the present system, the observed decreases in size at first reproduction demonstrate severe impacts of the alien predator even on life history traits of the prey populations. Life history responses to predation were also seen with respect to clutch size, which increased significantly in both Daphnia spp. and B. longirostris during the study period. The clutch size is influenced by an allocation trade-off between producing many small or a few large eggs (Smith \& Fretwell, 1974; Dorazio \& Lehman, 1983), and sizeselective predation by planktivorous fish is known also from other studies to induce the production of many small eggs in cladocerans (Dodson, 1989; Stibor, 1992).

The observed changes in body size and life-history characteristics may be interpreted as expressions of phenotypic plasticity within the present genotypes of the different zooplankton species. On the other hand, the study period encompassed 12 years of apparently directional and continuous selection on species with several to many generations per season. The study period thus covers about 30-40 generations of the dominant cladocerans. We argue that evolutionary changes are also likely to contribute to some of the observed changes in the zooplankton. However, based on the present results it is not possible to determine the relative contribution of genetic changes and phenotypic plasticity.

\section{ACKNOWLEDGEMENTS}


We would like to thank Laina Dalsbø, Jan Evjen, Ingrid Jensvoll and Frode Staldvik for their invaluable assistance in the field and laboratory work. We also acknowledge two anonymous referees for their helpful comments and suggestions. The study was financially supported by the Norwegian Research Council, the Norwegian Directorate for Nature Management, and the Environmental Department of the Finnmark County Governor.

\section{REFERENCES}

Agresti A. (2002) Categorical data analysis. Second edition. John Wiley \& Sons, Inc., Hoboken, New Jersey.

Amundsen P.-A., Bøhn T., Popova O.A., Staldvik F.J., Reshetnikov Y.S., Lukin A.A. \& Kashulin N.A. (2003) Ontogenetic niche shifts and resource partitioning in a subarctic piscivorous fish guild. Hydrobiologia, 497, 109-119.

Amundsen P.-A., Bøhn T. \& Våga G.H. (2004a) Gill raker morphology and feeding ecology of two sympatric morphs of European whitefish (Coregonus lavaretus). Annales Zoologici Fennici, 41, 291-300.

Amundsen P.-A., Knudsen R., Klemetsen A. \& Kristoffersen R. (2004b) Resource partitioning and interactive segregation between sympatric whitefish morphs. Annales Zoologici Fennici, 41, 301-307.

Amundsen P.-A., Staldvik F.J., Reshetnikov Y.S., Kashulin N., Lukin A., Bøhn T., Sandlund O.T. \& Popova O.A. (1999) Invasion of vendace Coregonus albula in a subarctic watercourse. Biological Conservation, 88, 405-413. 
Bolker B., Holyoak M., Krivan V., Rowe L. \& Schmitz O. (2003) Connecting theoretical and empirical studies of trait-mediated interactions. Ecology, 84, 1101-1114.

Brooks J.L. \& Dodson S.I. (1965) Predation, body size, and composition of plankton. Science, 150, 28-35.

Bøhn T. \& Amundsen P.-A. (1998) Effects of invading vendace (Coregonus albula L.) on species composition and body size in two zooplankton communities of the Pasvik River System, northern Norway. Journal of Plankton Research, 20, 243-256.

Bøhn T. \& Amundsen P.-A. (2001) The competitive edge of an invading specialist. Ecology, 82, 2150-2163.

Bøhn T., Sandlund O.T., Amundsen P.-A. \& Primicerio R. (2004) Rapidly changing life history during invasion. Oikos, 106, 138-150.

Bøhn, T., Amundsen, P.-A. \& Sparrow, A. (2008) Competitive exclusion after invasion? Biological Invasions, 10, 359-368.

Courchamp F., Chapuis J.-L. \& Pascal M. (2003) Mammal invaders on islands: impact, control and control impact. Biological Reviews, 78, 347-383.

Cox J.G. \& Lima S.L. (2006) Naivetè and an aquatic-terrestrial dichotomy in the effects of introduced predators. Trends in Ecology and Evolution, 21, 674-680.

Davis M.A. (2003) Biotic globalization: Does competition from introduced species threaten biodiversity? Bioscience, 53, 481-489.

Dawidowicz P. \& Gliwicz Z.M. (1983) Food of brook charr in extreme oligotrophic conditions of an alpine lake. Environmental Biology of Fishes, 8, 55-60.

DeMelo R., France R. \& McQueen D.J. (1992) Biomanipulaton: Hit or myth? Limnology and Oceanography, 37, 192-207. 
Diamond J.M. (1989) The present, past and future of human-caused extinctions.

Philosophical Transactions of the Royal Society of London series B-Biological Sciences, 325, 469-476.

Dodson S.I. (1988) Cyclomorphosis in Daphnia galeata mendotae Birge and D. retrocurva Forbes as a predator-induced response. Freshwater Biology, 19, 109-114.

Dodson S.I. (1989) The ecological role of chemical stimuli for the zooplankton: predatorinduced morphology in Daphnia. Oecologia, 78, 361-367.

Dorazio R.M. \& Lehman J.T. (1983) Optimal reproductive strategies in age-structured populations of zooplankton. Freshwater Biology, 13, 157-175.

Ebert D. (1993) The trade-off between offspring size and number in Daphnia magna: The influence of genetic, environmental and maternal effects. Archiv für Hydrobiologie, 4, 453-473.

Elliott J.M. (1994) Quantitative ecology and the brown trout. Oxford University Press, Oxford.

Galbraith M.G.J. (1967) Size-selective predation on Daphnia by rainbow trout and yellow perch. Transactions of the American Fisheries Society, 96, 1-10.

Gido K.B. \& Brown J.H. (1999) Invasions of North American drainages by alien fish species. Freshwater Biology, 42, 387-399.

Gliwicz Z.M. (1981) Food and predation in limiting clutch size of cladocerans.

Verhandlungen der Internationalen Vereinigung für Theoretische und Angewandte Limnologie, 21, 1562-1566.

Gliwicz Z.M. (1990) Food thresholds and body size in cladocerans. Nature, 343, 638-640.

Gliwicz Z.M. (2001) Species-specific population-density thresholds in cladocerans? Hydrobiologia, 442, 291-300. 
Gliwicz Z.M. \& Pijanowska J. (1989) The role of predation in zooplankton succession. In: Plankton ecology (Ed. U. Sommer), pp. 253-296. Springer-Verlag, Berlin.

Gophen M. (1985) Effect of fish predation on size class distribution of cladocerans in Lake Kinneret. Verhandlungen der Internationalen Vereinigung für Theoretische und Angewandte Limnologie, 22, 3104-3108.

Goulden C.E. \& Frey D.G. (1963) The occurrence and significance of lateral head pores in the genus Bosmina (Cladocera). Internationale Revue der Gesamten Hydrobiologie, $\mathbf{4 8}$, 513-522.

Hall D.J., Cooper W.E. \& Werner E.E. (1970) An experimental approach to the production dynamics and structure of freshwater animal communities. Limnology and Oceanography, 15, 839-928.

Hall D.J., Threlkeld S.T., Burns C.W. \& Crowley P.H. (1976) The size-efficiency hypothesis and the size structure of zooplankton communities. Annual Review of Ecology and Systematics, 7, 177-208.

Hamrin S.F. (1983) The food preference of vendace (Coregonus albula) in South Swedish forest lakes including the predation effect on zooplankton populations. Hydrobiologia, 101, 121-128.

Hamrin S.F. \& Persson L. (1986) Asymmetrical competition between age classes as a factor causing population oscillations in an obligate planktivorous fish species. Oikos, 47, 223-232.

Hrbáček J., Dvořakova M., Kořínek V. \& Procházkóva L. (1961) Demonstration of the effect of the fish stock on the species composition of zooplankton and the intensity of metabolism of the whole plankton association. Verhandlungen der Internationalen Vereinigung für Theoretische und Angewandte Limnologie, 14, 192-195. 
Kankaala P., Vasama A., Eskonen K. \& Hyytinen L. (1990) Zooplankton of Lake Ala-Kitka (NE-Finland) in relation to phytoplankton and predation by vendace (Coregonus albula). Aqua Fennica, 20, 81-94.

Karjalainen J., Turunen T., Helminen H., Sarvala J. \& Huuskonen H. (1997) Food selection and consumption of 0+ smelt (Osmerus eperlanus (L.)) and vendace (Coregonus albula (L.)) in pelagial zone of Finnish lakes. Archiv für Hydrobiologie Special Issues Advances in Limnology, 49, 37-49.

Karjalainen J. \& Viljanen M. (1993) Changes in the zooplankton community of Lake Puruvesi, Finland, in relation to the stock of vendace (Coregonus albula (L.)). Verhandlungen der Internationalen Vereinigung für Theoretische und Angewandte Limnologie, 25, 563-566.

Kaufman L. (1992) Catastrophic change in species-rich freshwater ecosystems: The lessons of Lake Victoria. Bioscience, 42, 846-858.

Kolar C.S. \& Wahl D.H. (1998) Daphnid morphology deters fish predators. Oecologia, 116, 556-564.

Lampert W. (1993) Phenotypic plasticity of the size at first reproduction in Daphnia: The importance of maternal size. Ecology, 74, 1455-1466.

Lampert W. \& Sommer U. (1997) Interactions. In: Limnoecology: The ecology of lakes and streams (Eds W. Lampert \& U. Sommer), pp. 160-253. Oxford University Press, New York.

Larsson P. \& Dodson S. (1993) Invited Review: Chemical communication in planktonic animals. Archiv für Hydrobiologie, 129, 129-155.

Lass S. \& Spaak P. (2003) Chemically induced anti-predator defences in plankton: a review. Hydrobiologia, 491, 221-239. 
Lazzaro X. (1987) A review of planktivorous fishes: Their evolution, feeding behaviours, selectivities, and impacts. Hydrobiologia, 146, 97-167.

Løvik J.E. \& Kjellberg G. (2003) Long-term changes of the crustacean zooplankton community in Lake Mjøsa, the largest lake in Norway. Journal of Limnology, 62, 143150.

Mellors W.K. (1975) Selective predation of ephippial Daphnia and the resistance of ephippial eggs to digestion. Ecology, 56, 974-980.

O'Brien W.J. (1979) The predatory-prey interaction of planktivorous fish and zooplankton. American Scientist, 67, 572-581.

O'Brien W.J. (1987) Planktivory by freshwater fish: Thrust and parry in the pelagia. In:

Predation: direct and indirect impacts on aquatic communities (Eds W.C. Kerfoot \& A. Sih), pp. 3-16. University of New England Press, Hanover, N.H.

Park K. (2004) Assessment and management of invasive alien predators. Ecology and Society, 9(2), 12. [online] URL: http://www.ecologyandsociety.org/vol9/iss2/art12/

Persson L., Byström P., Wahlström E. \& Westman E. (2004) Trophic dynamics in a whole lake experiment: size-structured interactions and recruitment variation. Oikos, 106, 263-274.

Pijanowska J. (1992) Anti-predator defence in three Daphnia species. Internationale Revue der Gesamten Hydrobiologie, 77, 153-163.

Pohnert G., Steinke M. \& Tollrian R. (2007) Chemical cues, defence metabolites and the shaping of pelagic interspecific interactions. Trends in Ecology and Evolution, 22, 198-204.

Primicerio R., Rossetti G., Klemetsen A. \& Amundsen P.-A. (2007) Impact of climate change on Alpine and Arctic lakes: effects on phenology and community dynamics. In: Arctic 
Alpine Ecosystems and People in a Changing Environment (Eds J.B. Ørbæk et al.), pp. 51-69. Springer Verlag, Berlin.

Salo J., Walls M., Rajasilta M., Sarvala J., Räsänen M. \& Salonen V.-P. (1989) Fish predation and reduction in body size in a Cladoceran population: palaeoecological evidence. Freshwater Biology, 21, 217-221.

Sandlund O.T., Næsje T.F. \& Kjellberg G. (1987) The size selection of Bosmina longispina and Daphnia galeata by co-occurring cisco (Coregonus albula), whitefish (C. lavaretus) and smelt (Osmerus eperlanus). Archiv für Hydrobiologie, 110, 357-363.

Sarvala J., Helminen H., Saarikari V., Salonen S. \& Vuorio K. (1998) Relations between planktivorous fish abundance, zooplankton and phytoplankton in three lakes of differing productivity. Hydrobiologia, 363, 81-95.

Ślusarczyk M. (1997) Impact of fish predation on a small-bodied cladoceran: limitation or stimulation? Hydrobiologia, 342, 215-221.

Smith C.C. \& Fretwell S.D. (1974) The optimal balance between size and number of offspring. American Naturalist, 108, 499-506.

Stabell O.B., Ogbebo F. \& Primicerio R. (2003) Inducible defences in Daphnia depend on latent alarm signals from conspecific prey activated in predators. Chemical Senses, 28, 141-153.

Stibor H. (1992) Predator induced life-history shifts in a freshwater cladoceran. Oecologia, 92, 162-165.

Stibor H. \& Lampert W. (2000) Components of additive variance in life-history traits of Daphnia hyalina: seasonal differences in the response to predator signals. Oikos, $\mathbf{8 8 ,}$ 129-138.

Strayer D.L., Eviner V.T., Jeschke J.M. \& Pace M.L. (2006) Understanding the long-term effects of species invasions. Trends in Ecology and Evolution, 21, 645-651. 
Svärdson G. (1976) Interspecific population dominance in fish communities of Scandinavian lakes. Report of the Institiute for Freshwater Research, Drottningholm, 55, 144-171.

Taylor B.E. \& Gabriel W. (1992) To grow or not to grow: optimal resource allocation for Daphnia. American Naturalist, 139, 248-266.

Tollrian R. (1995) Predator-induced morphological defences: costs, life history shifts, and maternal effects in Daphnia pulex. Ecology, 76, 1691-1705.

Tollrian R. \& Harvell C.D. (1999) The ecology and evolution of inducible defences. Princeton University Press, Princeton, NJ.

Viljanen M. (1983) Food and food selection of cisco (Coregonus albula L.) in a dysoligotrophic lake. Hydrobiologia, 101, 129-138.

Vonder Brink R.H. \& Vanni M.J. (1993) Demographic and life history response of the cladoceran Bosmina longirostris to variation in predator abundance. Oecologia, 95, 70-80.

Weber A. \& Declerck S. (1997) Phenotypic plasticity of Daphnia life history traits in response to predator kairomones: genetic variability and evolutionary potential. Hydrobiologia, 360, 89-99.

Weider L.J. \& Pijanowska J. (1993) Plasticity of Daphnia life histories in response to chemical cues from predators. Oikos, 67, 385-392.

Witte F., Goldschmidt T., Wanink J., Van Oijen M., Goudswaard K., Witte-Maas E. \& Bouton N. 1992. The destruction of an endemic species flock. Quantitative data on the decline of the haplochromine cichlids of Lake Victoria. Environmental Biology of Fishes, 34, 1-28.

Worm B., Lotze H.K., Hillebrand H.H. \& Sommer U. (2002) Consumer versus resource control of species diversity and ecosystem functioning. Nature, 417, 848-851.

Zaret T.M. (1980) Predation and freshwater communities. Yale University Press, New Haven. 
Zaret T.M. \& Paine R.T. (1973) Species introduction in a tropical lake. Science, 182, 449-455. 
Table 1. Statistical results of linear regression of body length of female cladocerans with eggs versus year (see also Fig. 4). Statistically significant P-values are written in bold.

\begin{tabular}{lrrrrrrr}
\hline \hline & \multicolumn{2}{c}{ Daphnia spp. } & \multicolumn{2}{c}{ B. longispina } & \multicolumn{2}{c}{ B. longirostris } \\
\cline { 2 - 7 } & Estimate & P & Estimate & P & Estimate & P \\
\hline \multirow{2}{*}{ Intercept } & 0.707 & $<\mathbf{0 . 0 0 1}$ & 0.489 & $<\mathbf{0 . 0 0 1}$ & 0.347 & $<\mathbf{0 . 0 0 1}$ \\
Slope & -0.007 & $<\mathbf{0 . 0 0 1}$ & -0.008 & $<\mathbf{0 . 0 0 1}$ & -0.002 & $<\mathbf{0 . 0 0 1}$ \\
\hline
\end{tabular}


Table 2. Statistical results of logistic regression of egg/ephippium presence versus body size and year for all three Cladocera species (egg/ephippium presence $=$ constant + body length + year). Positive estimate of the year parameter means that probability of having eggs increases with time at a given body size, and that size at first reproduction is decreasing (see also Fig. 5). Statistically significant P-values are written in bold.

\begin{tabular}{|c|c|c|c|c|c|c|}
\hline \multirow[b]{2}{*}{ Parameter } & \multicolumn{2}{|c|}{ Daphnia spp. } & \multicolumn{2}{|c|}{ B. longispina } & \multicolumn{2}{|c|}{ B. longirostris } \\
\hline & Estimate & $\mathrm{P}$ & Estimate & $\mathrm{P}$ & Estimate & $\mathrm{P}$ \\
\hline Constant & -235.522 & $<0.05$ & -840.959 & $<0.001$ & -285.830 & $<0.001$ \\
\hline Body size* & 12.490 & $<0.001$ & 32.753 & $<0.001$ & 39.476 & $<0.001$ \\
\hline Year & 0.114 & $<0.05$ & 0.413 & $<0.001$ & 0.136 & $<0.001$ \\
\hline
\end{tabular}


Table 3. Statistical results from logistic regression of number of eggs (one or two) per clutch versus body length and year for Daphnia spp. and B. longirostris (number of eggs $=$ constant + body length + year). Statistically significant P-values are written in bold.

\begin{tabular}{lrrrc}
\hline \hline & \multicolumn{3}{l}{ Daphnia spp. } & \multicolumn{2}{l}{ B. longirostris } \\
\cline { 2 - 5 } Parameter & Estimate & $\mathrm{P}$ & Estimate & $\mathrm{P}$ \\
\hline & & & & \\
\hline Constant & -305.523 & $<\mathbf{0 . 0 1}$ & -324.874 & $<\mathbf{0 . 0 0 1}$ \\
Body length & 15.258 & $<\mathbf{0 . 0 0 1}$ & 44.554 & $<\mathbf{0 . 0 0 1}$ \\
Year & 0.147 & $<\mathbf{0 . 0 1}$ & 0.154 & $<\mathbf{0 . 0 1}$ \\
\hline
\end{tabular}




\section{Legends to figures:}

Fig. 1. Relative contribution of vendace in gillnet catches from the pelagic fish community in Ruskebukta during the time period from 1991 to 2002. Stippled line represents asymptotic power curve fitted to the data.

Fig. 2. Total density (a), species diversity (b) and relative species composition (c) of the crustacean zooplankton community in Ruskebukta during the study period. Figures include all cladocerans, adult copepods and copepodite stages.

Fig. 3. Relative abundance of B. longispina as a proportion of total Bosmina spp. abundance during the study period. Stippled line represents power curve fitted to the data $\left(\mathrm{R}^{2}=0.622\right.$, $\mathrm{P}<0.05)$

Fig. 4. Annual variations in mean body lengths during the study period of females with eggs of Daphnia spp. (circles), B. longispina (triangles) and B. longirostris (squares). Bars represent 95\% confidence interval. For equations and statistics of regression lines, see Table 1.

Fig. 5. Size at first reproduction (body length with 50\% egg-bearing females, EL50) of $B$. longispina (triangles) and B. longirostris (squares) during the study period. Filled symbols represent years where the relationship in the logistic regression between egg-presence and body length was significant, whereas non-significant values are showed with open symbols. Regression lines of the relationships between size at first reproduction and year are included. For equations and statistics of regression lines, see Table 2. 


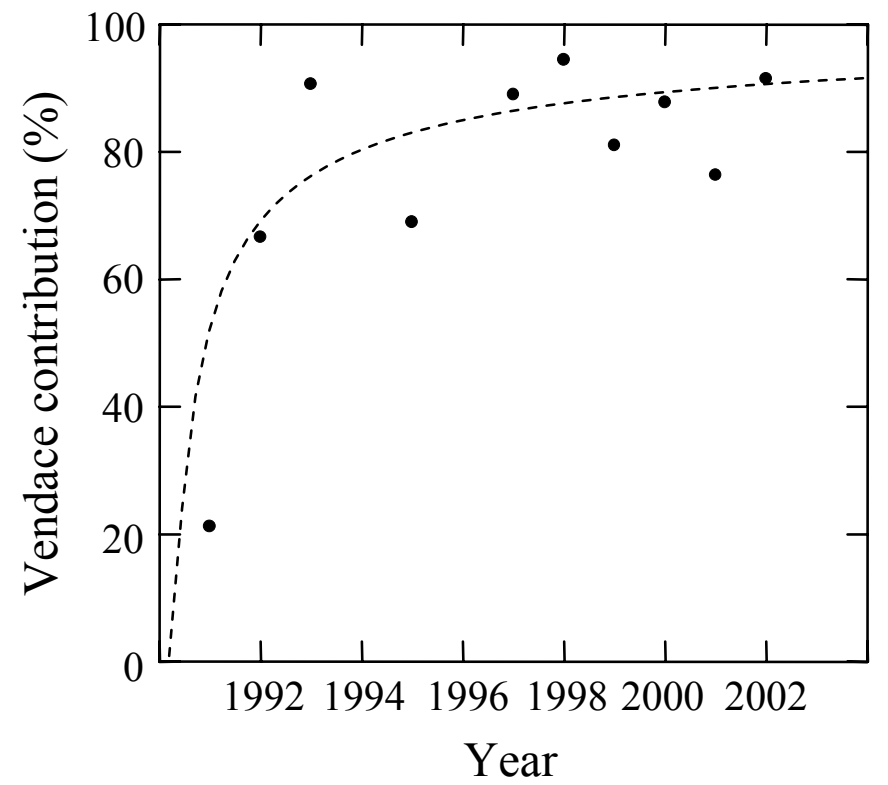


a)

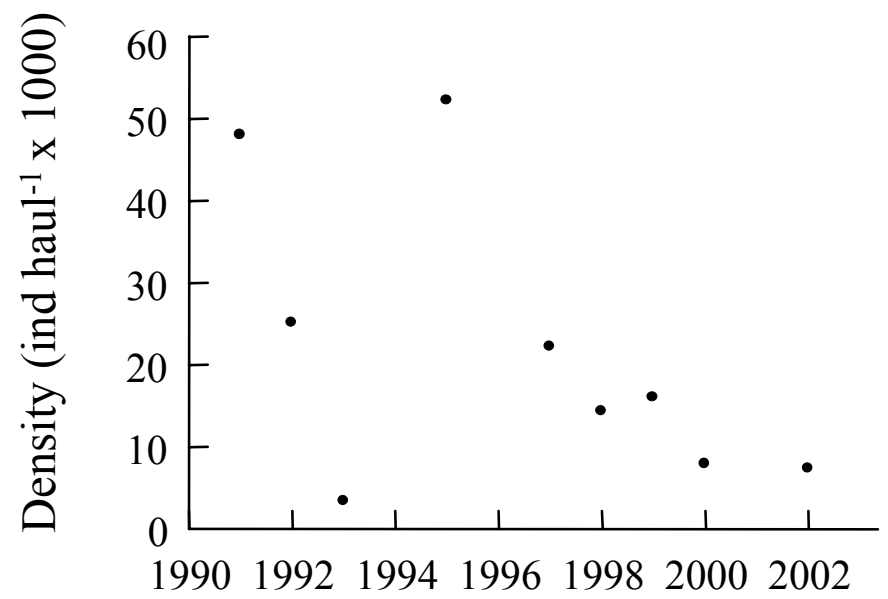

b)

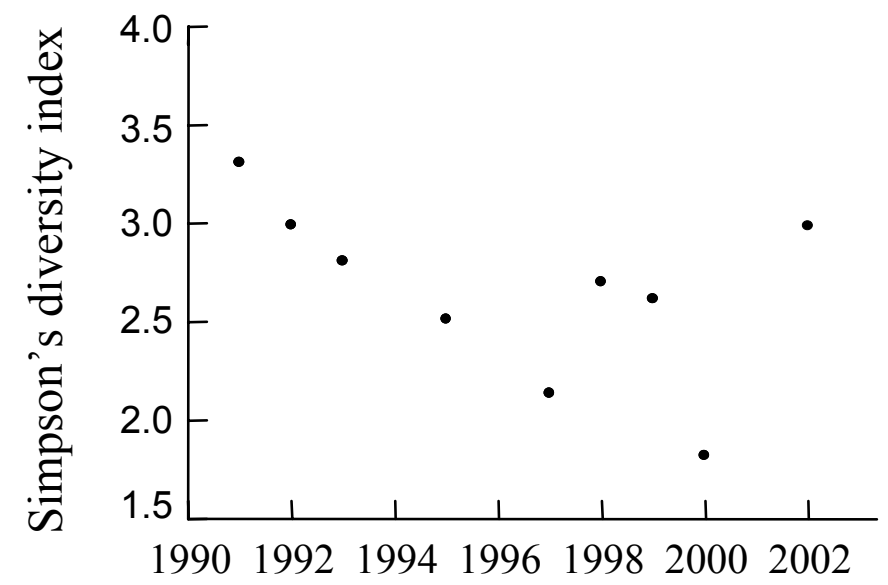

c)

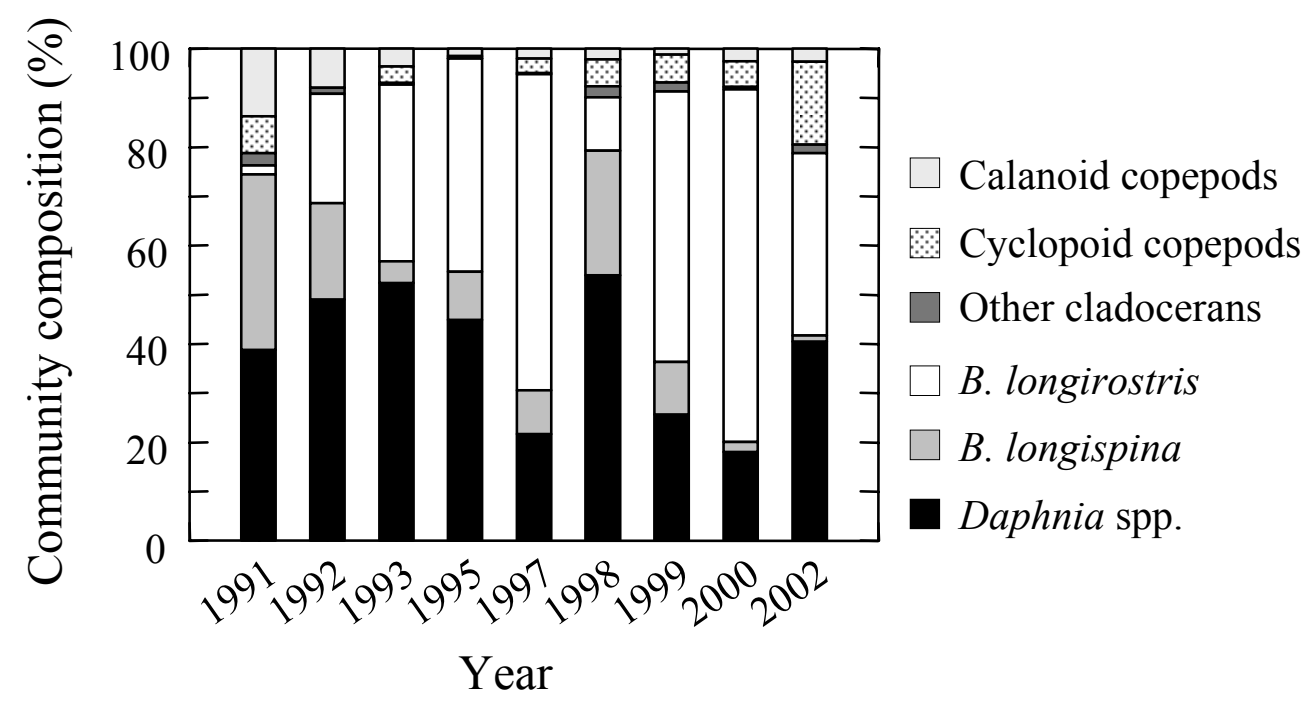




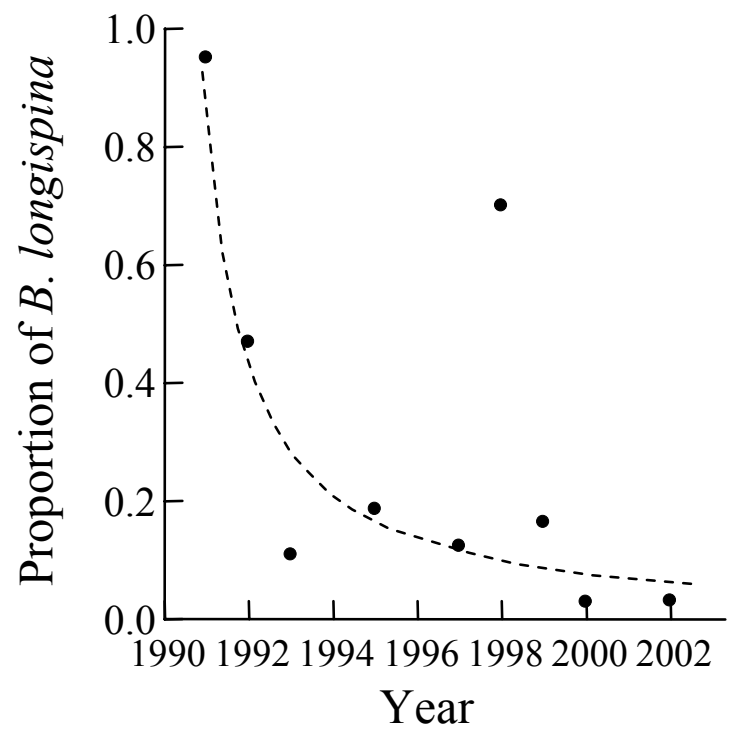




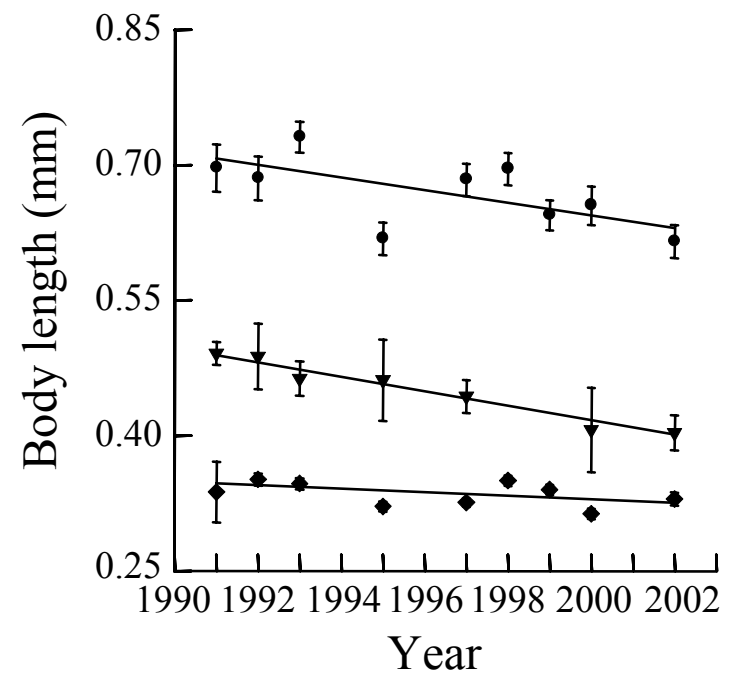




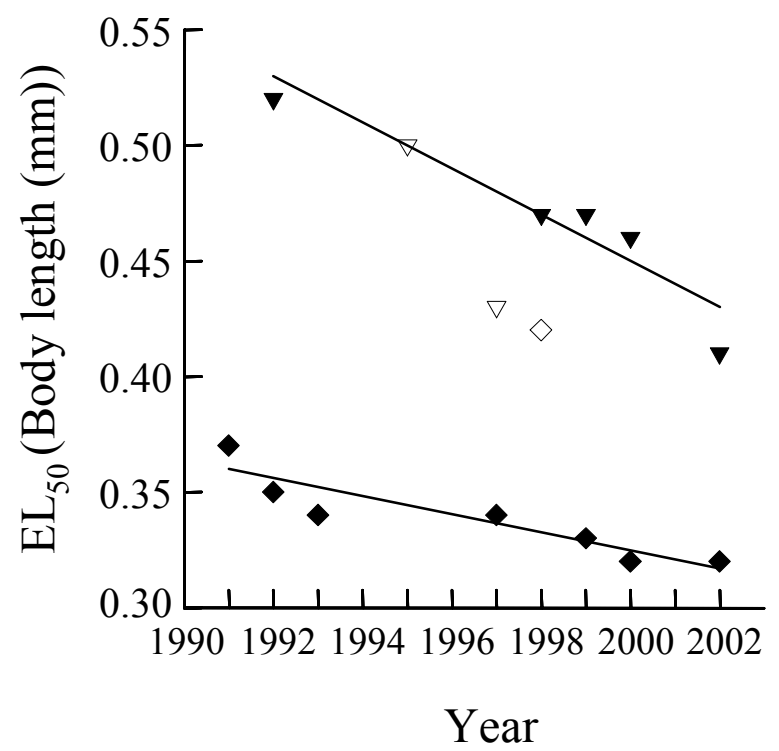

